\title{
1-stage CoMT-CAMD: An approach for integrated design of ORC process and working fluid using PC-SAFT
}

\author{
Johannes Schilling ${ }^{\mathrm{a}}$, Matthias Lampe ${ }^{\mathrm{a}}$, Joachim Gross ${ }^{\mathrm{b}}$, André Bardow ${ }^{\mathrm{a}, *}$ \\ ${ }^{a}$ Chair of Technical Thermodynamics, RWTH Aachen University, 52056 Aachen, Germany \\ ${ }^{b}$ Institute of Thermodynamics and Thermal Process Engineering, Stuttgart University, \\ Pfaffenwaldring 9, 70569 Stuttgart, Germany
}

\begin{abstract}
Organic Rankine Cycles (ORC) transform low-temperature heat into electrical power. To exploit the full potential of a low-temperature heat source, the ORC system is tailored to the specific application. Tailoring an ORC system is challenging, since both process and working fluid have to be optimized simultaneously. We present an approach for integrated design of ORC process and working fluid that enables tailoring an ORC process and the working fluid in a single optimization problem. This approach builds upon the continuous-molecular targeting - computer-aided molecular design (CoMT-CAMD) approach presented by Lampe et al. [1. Here, a detailed process model is combined with a modern model of the working fluid, the perturbed-chain statistical associating fluid theory (PC-SAFT) equation of state. A group contribution approach for PC-SAFT is integrated to allow the computer-aided molecular design (CAMD) of novel fluids within the optimization. In this work, we formulate the corresponding mixed integer nonlinear program (MINLP) problem and solve it in one stage by deterministic optimization combining CoMT and outer-approximation. We therefore call the approach 1-stage CoMT-CAMD. 1-stage CoMT-CAMD problems can

\footnotetext{
* Corresponding author

Email address: andre.bardow@1tt.rwth-aachen.de (André Bardow )
}

DOI: $10.1016 /$ j.ces.2016.04.048

(C) 2016. This manuscript version is made available under the CC-BY-NC-ND 4.0 license http://creativecommons.org/licenses/by-nc-nd/4.0/
\end{abstract}


be solved efficiently using commercial solvers enabling both single-objective and multi-objective optimization of process and working fluid. The presented approach is employed in two ORC case studies. The first case study outlines the applicability for single-objective and multi-objective optimization for combined heat and power generation. In the second case study, a detailed turbine model is considered within the optimization showing the possibility of modelling the process components in a more detailed manner. The 1-stage CoMT-CAMD approach thus efficiently solves complex integrated design problems based on a consistent thermodynamic picture.

Keywords: Integrated process and fluid design, Computer-aided Molecular Design, Continuous-Molecular Targeting, PC-SAFT, Organic Rankine Cycle

\section{Introduction}

Integrating computer-aided molecular design (CAMD) into product and process design is an important and emerging problem in engineering: The problem of integrated design of molecules and process arises, e.g., for design of 5 solvents $[2,3,4,5,6,6$, , refrigerants $[8,9]$ and the design of adsorption materials [10].

In particular, integrated fluid and process design is a crucial challenge in the design of Organic Rankine Cycles (ORC) as recently reviewed by Linke et al. [1]. Power generation from renewable sources is a key need for sustainable societies. ORCs enable power generation from low-temperature heat [12. Lowtemperature heat can be captured from various renewable heat sources, e.g., solar heat [13], geothermal heat [14, biomass [15], or waste heat from industrial [16] as well as automotive applications [17. To exploit the full potential of a heat source, the ORC has to be tailored to the specific application. In order to

15 tailor an ORC, process and working fluid have to be optimized simultaneously as pointed out in several recent reviews [11, 18].

Today, fluid selection and process optimization are carried out separately following a two-stage approach [13, 15, 19]: In a first stage, promising working 
fluid candidates are preselected based on experience and heuristic guidelines defining favorable fluid properties. In a second stage, an individual process optimization is performed for each preselected working fluid candidate. For the first preselection stage, a variety of heuristic criteria have been proposed. Bao and Zhao [18] reviewed shortcomings in common heuristics for preselection. If the preselection fails, the two-stage approach leads to suboptimal solutions.

Thus, recent reviewers recommend to directly integrate the fluid selection into the process optimization to obtain overall optimal solutions [2, 11, 18, 19]. An integrated design approach captures the interdependency of process and fluid, but leads to a large scale complex non-convex mixed integer nonlinear programming (MINLP) problem 20, since a discrete degree of freedom is added so to the process optimization for each working fluid. Thus, systematic solution approaches for the integrated design of process and fluid have been proposed. Recently, Linke et al. [11] reviewed systematic approaches for the integrated design of ORCs: Papadopoulos et al. 21] show the merits of CAMD for ORC working fluids considering pure working fluids. In a first stage, a set of pure working fluid candidates is obtained using a CAMD formulation within a multiobjective optimization. The working fluid candidates are assessed in subsequent process optimizations. The optimization problem is solved by simulated annealing. The approach is extended for identifying working fluid mixtures and also for allowing a process-level objective function [22]. The fluid properties are pre40 dicted using a group contribution (GC) method and the cubic Peng-Robinson equation of state (EoS). Palma-Flores et al. [23] also present an optimizationbased CAMD approach using a GC approach and a cubic EoS to predict the fluid properties. In a first stage, they perform a single-objective optimization to obtain a set of pure working fluid candidates. The optimization problem is solved 45 by deterministic optimization. In a second stage, the working fluid candidates are assessed in a process simulation using 3 different process configurations.

CAMD approaches are commonly based on a set of target properties. If these target properties are defined a priori, the application of CAMD approaches has become relatively straight forward, e.g., for working fluid design for ORC appli- 
50 design [9, 25, 27] as recently reviewed by $\mathrm{Ng}$ et al. 28. However, a priori definition of favorable target properties is challenging. Targeting approaches have been proposed, which aim at identifying favorable fluid properties, so called targets. These targeting approaches allow solving the integrated design problem in a second stage based on these targets. Eden et al. 29] present a targeting approach for process and product design based on property clustering techniques. Bardow et al. 3 integrate the design of process and solvent in the continuous-molecular targeting (CoMT) framework, which combines a model the perturbed-chain statistically associating fluid theory (PC-SAFT) equation of state [30]. The CoMT framework directly leads to molecular targets. CoMT has been applied to solvent design [3, 6] and ORCs [31] for integrated design of process and fluids. In a first stage of the CoMT framework, the pure component a nonlinear programming (NLP) problem. The NLP results in a hypothetical optimal working fluid, the target, along with the corresponding optimal process parameters. In a second stage, real working fluids, which show similar performance as the hypothetical optimal working fluid, are identified. Within this second stage, the so-called structure-mapping, a second degree Taylor approximation of the objective function is used to estimate the objective function value of the real working fluids. The structure-mapping allows the selection of working fluids from a database 31. Schilling et al. 32 proposed an adaptive refinement of the Taylor approximation for the database search. Lampe et al. [1] extend the structure-mapping by a CAMD formulation and a GC approach for PC-SAFT [33] to identify novel fluids during structure-mapping, in the so-called CoMT-CAMD approach. Thereby, the previous database search is transformed into a mixed-integer quadratic programming (MIQP) problem considering the Taylor approximation as objective function. 
A targeting approach has also recently been proposed by Roskosch and Atakan for the integrated design of heat pumps using the cubic Peng-Robinson EoS [8]. In this approach, optimal thermo-physical properties (e.g., critical pressure, critical temperature) are identified in a first stage. In a second stage, working fluids with similar properties are identified from a database.

Progress in the numerical techniques and improved MINLP solvers enable the integrated design in one-stage using even modern thermodynamic models of the fluid. Pereira et al. 34 present an optimization-based one-stage approach for integrated solvent and process design using the statistical associating fluid theory for potentials of variable attractive range (SAFT-VR) to model the solvent. The search space of the considered fluids is still limited to linear alkanes, but the approach shows the merits and relevance of a physically-based solvent model for fluid design. Zhou et al. [35] present an approach for integrated solvent and process design combining a model for reaction kinetics and a GC method. Here, solvent descriptors determined from quantum chemical density functional theory calculations enable the simultaneous optimization of process operations and the molecular structure of the solvent. Recently, Burger et al. [4] proposed a hierarchical approach for integrated design of process and solvent using simplified short-cut models of the process and SAFT- $\gamma$ Mie as solvent model.

In this work, we present a one-stage approach for the integrated design of ORC process and working fluid using a detailed process model and a modern model of the working fluid, the PC-SAFT EoS. This approach is based on the two-stage CoMT-CAMD approach presented by Lampe et al. 1]. However, the two-stage approach is conceptually avoided. Instead, the CAMD of novel fluids is directly combined with the process model and the fluid model. Thereby, the full process-level objective function and constraints are linked to the molecular design optimization. The adapted CoMT-CAMD approach is linked to an outer-approximation formulation to identify molecular structures in one stage. We therefore call the approach 1-stage CoMT-CAMD. The link is enabled by the deterministic MINLP solver DICOPT, which combines the CoMT problem 
with outer-approximation. 1-stage CoMT-CAMD identifies the optimal working fluid and the corresponding process parameters in one single optimization of the MINLP problem. Due to the efficient solution procedure, multi-objective optimization can be employed to capture trade-offs within the fluid design. A preliminary version of this work has been presented in a conference paper [36]. The paper is structured as follows: In Section 2 , the problem formulation of the MINLP as well as the CAMD-based fluid model is presented. In Section, 3, the one-stage approach is applied to a single and a multi-objective optimization of two ORC design case studies. In Section 4, advantages and disadvantages of the one-stage approach are discussed based on the case studies. In Section 5 conclusions are drawn.

\section{Integrated one-stage design of process and working fluid}

The presented 1-stage CoMT-CAMD approach for the integrated design of process and working fluid requires a model of the process and a model of the working fluid describing its properties at different states. Here, the fluid is modeled by the PC-SAFT equation of state. This fluid model is extended by a CAMD formulation and a GC approach based on PC-SAFT to integrate the fluid design as degree of freedom into the optimization. The extended fluid model is coupled with the process model to capture all process-related trade-offs. A detailed description of the MINLP problem formulation is given in Section 2.1. In Section 2.2, the extended working fluid model is described.

\subsection{Problem formulation for integrated design of process and working fluid}

A generic MINLP problem formulation for integrated design of process and working fluid is presented by Gani [20]. Originally, a single-objective optimiza- 
tion is considered. Here, we also employ multi-objective optimization. The full problem can thus be formulated as:

$$
\begin{array}{lll}
\max _{x, y^{\mathrm{S}}} & \left(f_{1}(x, \theta), f_{2}(x, \theta), \ldots f_{\mathrm{k}}(x, \theta)\right)^{\mathrm{T}} \\
\text { s.t. } & g_{1}(x, \theta) \leq 0 \\
& g_{2}(x, \theta)=0 & \\
& \theta=h(x, z) & \\
& z=G C \cdot y^{\mathrm{S}} & \text { PC }-\mathrm{SAFT} \\
& F_{1} \cdot y^{\mathrm{S}}=0 \\
& F_{2} \cdot y^{\mathrm{S}} \leq 0 \\
& x_{\mathrm{lb}} \leq x \leq x_{\mathrm{ub}} \in \mathbb{R}^{\mathrm{n}} \\
& y_{\mathrm{lb}}^{\mathrm{S}} \leq y^{\mathrm{S}} \leq y_{\mathrm{ub}}^{\mathrm{S}} \in \mathbb{Z}^{1} &
\end{array}
$$

Herein, the process model encompasses one or more objective functions $\left(f_{1}(x, \theta)\right.$, $\left.f_{2}(x, \theta), \ldots f_{\mathrm{k}}(x, \theta)\right)$, equality constraints $g_{2}(x, \theta)$ as well as inequality constraints $g_{1}(x, \theta)$. Since an equilibrium fluid model is currently employed, any objective function based on equilibrium properties can be considered (e.g., net power output, thermal or exergy efficiency). Recently, PC-SAFT has been extended to calculate transport properties [37, 38. The knowledge of transport properties would also allow equipment sizing and thus the use of economic objectives. The process model depends on two kinds of variables: process variables $x$ (e.g., mass flow rate or pressure levels) and fluid properties $\theta$ (e.g., enthalpies or entropies) at different states. Non-thermodynamic properties (e.g., global warming potential (GWP) or flammability) could be added to the model as demonstrated in earlier CAMD approaches [21]. In general, structural degrees of freedom can also be considered on the process level to represent different flowsheets. Here, we consider only continuous variables. The fluid properties $\theta$ are calculated by the fluid model $\theta=h(x, z)$. Here, the working fluid is modeled by the PCSAFT EoS. The fluid properties depend on both the process variables $x$ and a set of pure component parameters $z$ representing the fluid. To integrate the 

lation is employed allowing the design of novel promising working fluids. In this CAMD formulation, each working fluid is characterized by its molecular structure $y^{\mathrm{S}}$. The vector $y^{\mathrm{S}}$ represents the number of functional groups constituting the molecular structure of the fluid (see Section 2.2). To link the pure comimation see Floudas [42]). We use the software GAMS (version 24.6.1) 43] and the deterministic MINLP solver DICOPT [4] with the subsolvers SNOPT [45] and BARON 46] to solve the NLPs and MIPs, respectively. 
1-stage CoMT-CAMD is based on the two-stage CoMT-CAMD approach presented by Lampe et al. [1. Both approaches use the same CAMD formulation, GC approach and fluid model (Figure 1). Also, 1-stage CoMT-CAMD initially solves the CoMT problem to identify a hypothetical optimal working fluid by relaxation of the pure component parameters, the so-called target. However in the two-stage CoMT-CAMD approach, a decomposition is employed and CAMD is not directly integrated into the fluid and process design. Thus, a second stage, the structure-mapping, is needed to identify real working fluids based on an approximation of the objective and constraints. Additionally, a predefined convex hull is required in the CoMT problem for the two-stage approach. Schilling et al. 32 propose an adaptive strategy refining the approximation in the structure-mapping iteratively for database search. 1-stage CoMT-CAMD systematically refines approximations of the objective and constrains based on the outer-approximation formulation. This strategy enables the identification of real working fluids in a single stage. The integration of CAMD into the one-stage design procedure for fluid and process also removes the need to estimate the convex hull around the structurally feasible working fluids, which is otherwise needed in the first stage of the two-stage approach.

The resulting MINLP problem can be solved as a single-objective or a multiobjective optimization. The solution of a single-objective optimization is one single optimal working fluid and the corresponding optimal process parameters. CAMD should usually provide a list of candidates to allow considering aspects not covered by the model or model inaccuracies. We therefore use integer cuts 42 to obtain a ranked list of optimal working fluids (Figure 1). Here, the MINLP is solved repeatedly, wherein the previous solutions are excluded from the feasible design space. To reduce computation effort, the CoMT solution of the first MINLP is saved and set as initial value for the subsequent MINLPs. The identified ranking can be assessed for further criteria. The solution of a multi-objective optimization is a Pareto front of potential working fluids. The Pareto front can be generated using multi-objective optimization methods (e.g., 
a) two-stage CoMT-CAMD
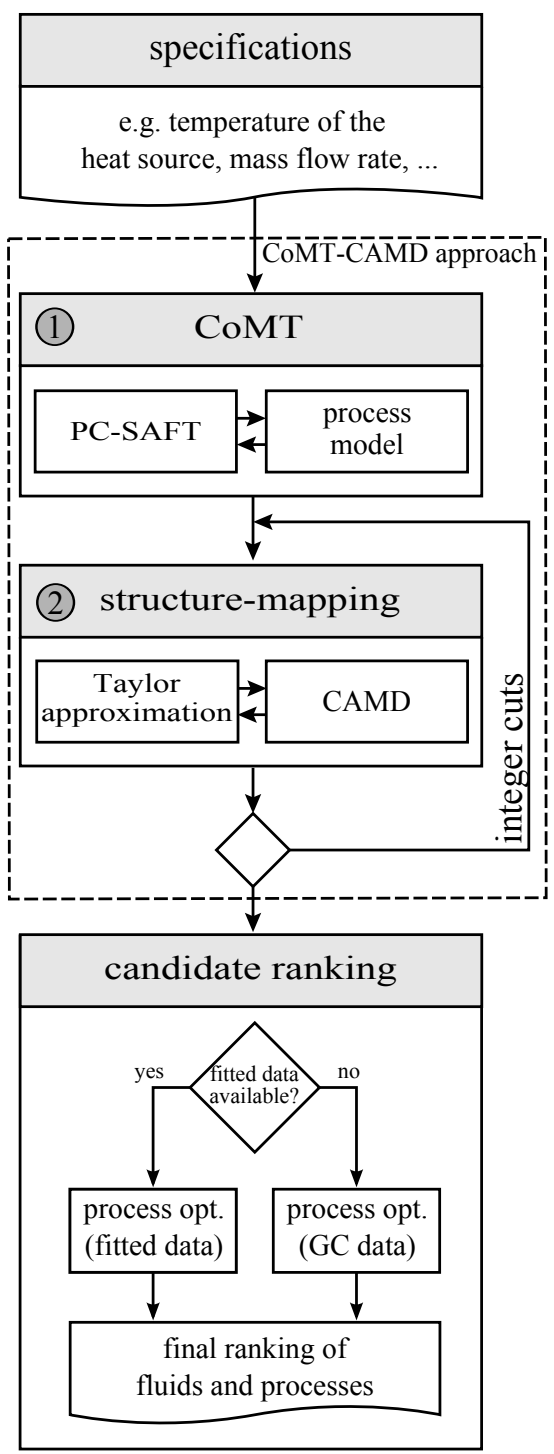

b) 1-stage CoMT-CAMD

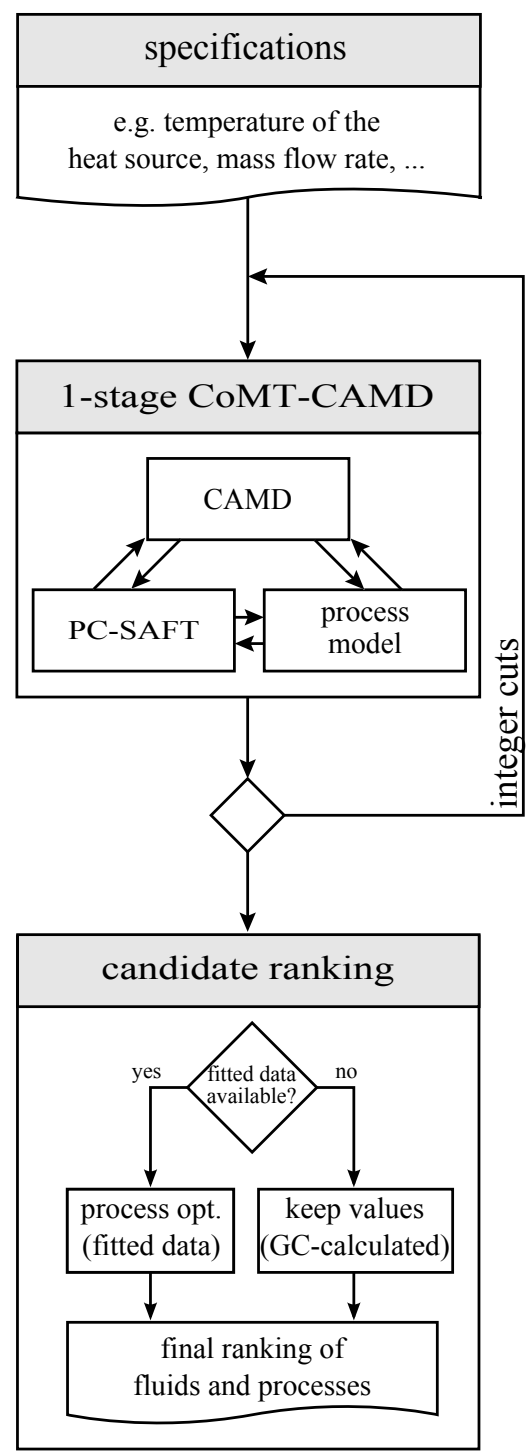

Figure 1: Comparison of the frameworks of a) the two-stage CoMT-CAMD approach [1] and b) 1-stage CoMT-CAMD. Integer Cuts can be used to obtain a ranked list of optimal working fluids. The accuracy of the ranking can be increased by a final process optimization considering pure component parameters fitted to measurement data if available. 

more advanced methods [49]).

Finally, it is also important to take into account that the GC approach introduces uncertainties in the result [33, which can have significant impact on the performance [22] To increase accuracy of the result, a final process optimizaparameters fitted to measurement data for vapor-liquid equilibrium (VLE) and liquid densities if available (Figure 1). The impact of the uncertainties of the GC approach is discussed in Section 4.2 .

\section{2. $C A M D$ based on group-contribution PC-SAFT}

220 fluid is modeled by the perturbed-chain statistical associating fluid theory (PCSAFT) equation of state [30 including contributions for polar components [50, 51. In this fluid model, working fluids are represented by a set of 3 to 7 pure component parameters. In the presented work, non-associative and nonapproach 33 .

The PC-SAFT EoS is based on the residual Helmholtz energy. Using a Helmholtz energy model ensures a consistent picture of all equilibrium properties of the fluid. Absolute caloric properties can be calculated if a reference property is known. For this purpose, we use the heat capacity of the ideal gas $c_{\mathrm{p}}^{\text {ig }}$. The two-stage CoMT-CAMD approach needs quantitative structure-property relationships (QSPR) to calculate the ideal gas heat capacity $c_{\mathrm{p}}^{\mathrm{ig}}$ and the molar mass since only the pure component parameters $z$ were known. In the presented 1-stage CoMT-CAMD approach, the molecular groups $y^{\mathrm{S}}$ are available during 
design. Thus, the heat capacity of the ideal gas $c_{\mathrm{p}}^{\mathrm{ig}}$ can be calculated from the molecular structure of the working fluid $y^{\mathrm{S}}$ by Joback's first-order groupcontribution method 52 (see Appendix A.1 for details). Caloric properties such as the absolute enthalpy $h$ can thus be calculated for a given pressure $p$ and temperature $T$ based on an arbitrary reference temperature $T_{0}$ by:

$$
h=h^{\mathrm{res}}(p, T, z)+h^{\mathrm{id}}\left(y^{\mathrm{S}}, T\right)=\underbrace{h^{\mathrm{res}}(p, T, z)}_{\text {PC-SAFT }}+\int_{T_{0}}^{T} \underbrace{c_{\mathrm{p}}^{\mathrm{ig}}\left(y^{\mathrm{S}}, \tilde{T}\right)}_{\text {Joback }} \mathrm{d} \tilde{T},
$$

where $h^{\text {res }}$ denotes the residual contribution calculated with PC-SAFT and $h^{\text {id }}$ denotes the ideal contribution calculated from the heat capacity of the ideal gas $c_{\mathrm{p}}^{\mathrm{ig}}$. The molar mass is also calculated exactly from the molecular structure of the working fluid avoiding the QSPR model used in the two-stage design.

To connect the PC-SAFT EoS to a CAMD formulation, the homosegmented GC approach from Sauer et al. 33] is employed. This so-called GPC-SAFT approach relates the pure component parameters of PC-SAFT to the molecular structure of the fluid. The group contributions are fitted to VLE data and liquid densities from a database for a range of pure fluids. Here, we limit the molecular design space of the CAMD formulation to prevent extrapolation from this database. Thereby, we use the highest accuracy of the CAMD formulation (see Section 4.2 for details). The limit is considered in the inequality constraints $F_{2} \cdot y^{\mathrm{S}} \leq 0$ in Problem 11. In GPC-SAFT, the pure component parameters are calculated by the mixing rules of Vijande et al. [53]:

$$
\begin{aligned}
& p_{1}:=m=\sum_{i \in I} n_{i} \cdot m_{i}, \\
& p_{2}:=m \cdot \sigma^{3}=\sum_{i \in I} n_{i} \cdot m_{i} \cdot \sigma_{i}^{3}, \\
& p_{3}:=m \cdot \epsilon / k=\sum_{i \in I} n_{i} \cdot m_{i} \cdot(\epsilon / k)_{i}, \\
& p_{4}:=\mu=\sum_{i \in I} n_{i} \cdot \mu_{i},
\end{aligned}
$$

where $n_{i}$ is the number of groups of type $i$ in the molecular structure represented by the vector $y^{\mathrm{S}}=\left(n_{1}, n_{2}, \ldots n_{\mathrm{m}}\right)^{\mathrm{T}}$. The vector $\tilde{z}_{i}=\left(m_{i}, \sigma_{i},(\epsilon / k)_{i}, \mu_{\mathrm{i}}\right)^{\mathrm{T}}$ contains 
the group contributions to the pure component parameters (see Appendix A.2 for details). In this work, 20 functional groups are employed: $-\mathrm{CH}_{3},-\mathrm{CH}_{2}-$ ${ }_{240},>\mathrm{CH}-$ and $>\mathrm{C}\left\langle\right.$ for alkanes, $=\mathrm{CH}_{2},=\mathrm{CH}-$ and $>\mathrm{C}=$ for alkenes, $-\mathrm{C} \equiv \mathrm{CH}$ for 1-alkynes, $>\mathrm{C}^{\mathrm{Arom}}=, \mathrm{CH}^{\mathrm{Arom}}=,>\mathrm{CH}^{\text {Pent }}-,>\mathrm{CH}_{2}^{\text {Pent }}-,>\mathrm{CH}^{\mathrm{Hex}}-$ and , $\mathrm{CH}_{2}^{\mathrm{Hex}}-$ for cyclic components with alkyl side groups, $-\mathrm{CH}=\mathrm{O}$ for aldehydes, $>\mathrm{C}=\mathrm{O}$ for ketones, $-\mathrm{O}-\mathrm{CH}_{3}$ and $-\mathrm{O}-\mathrm{CH}_{2}-$ for ethers, $-\mathrm{O}-\mathrm{CH}=\mathrm{O}$ for formats and $-\mathrm{O}-(\mathrm{C}=\mathrm{O})-$ for esters.

SAFT approaches were shown to provide accurate predictions of fluid behavior [54]. However, calculations are more demanding than for classical EoS, e.g., cubic EoS. Therefore, we perform all process calculations and all thermodynamic calculations of PC-SAFT in external equations basically providing a black-box model to GAMS. GAMS forwards the working fluid parameters calculated from the molecular structure $y^{\mathrm{S}}$ as well as the process variables $x$ to the external equations. The working fluid parameters are the pure component parameters of PC-SAFT $z$, the parameters needed for Joback's GC method and the molar mass. The external equations return the objective function value $f$, the process constraints $g$ and $h$ and first-order derivatives of these values to the optimization problem in GAMS (for details on external equations in GAMS see chapter 28 in [43]). Hereby, stable computations are enabled. However, the external calculations prevent the use of global MINLP solvers, which still rely on models given in explicit form [55]. To also capture possible local maxima, we employ integer cuts 42 to generate a ranking of candidates.

\section{Case studies and results}

The presented 1-stage CoMT-CAMD approach is demonstrated in two case studies for integrated design of ORC process and working fluid. In case study 1 , a geothermal $\mathrm{ORC}$ at $120^{\circ} \mathrm{C}$ based on Heberle and Brüggemann [14] is tailored using a single-objective optimization to demonstrate the general applicability of the approach (Section 3.1). Additionally, multi-objective optimization for the generation of combined heat and power is presented. In case study 2 (Sec- 
tion 3.2 , the process model is extended by a detailed model for preliminary turbine design [56]. The integrated design of the extended process and working fluid is performed for a solarthermal ORC with regenerator at $380^{\circ} \mathrm{C}$ based on Casati et al. [57.

\subsection{Case study 1: Geothermal ORC}

In case study 1, the 1-stage CoMT-CAMD approach is applied to the integrated design of process and working fluid of a subcritical, non-regenerated ORC based on Heberle and Brüggemann [14] (Figure 2). Water from a geothermal well is considered as a heat source with an inlet temperature of $T_{\mathrm{HC} \text {,in }}=120^{\circ} \mathrm{C}$ and a constant mass flow rate of $\dot{m}_{\mathrm{HC}}=66 \mathrm{~kg} \mathrm{~s}^{-1}$ (Table 1 ).
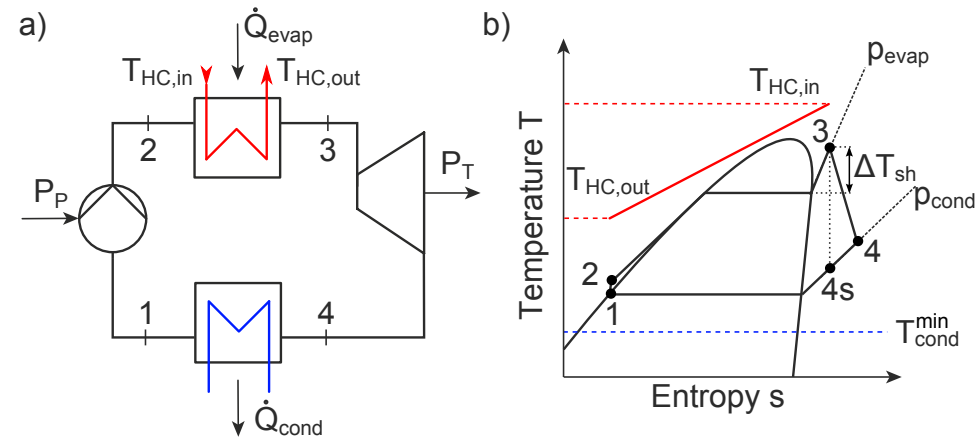

Figure 2: ORC process of case study 1 in (a) flowsheet and (b) temperature-entropy diagram.

The integrated design of process and working fluid is first performed based on a single-objective optimization. Here, the net power output $P_{\text {net }}$ is considered as objective function, since for geothermal applications the heat source is given and we want to get the most power out of it. Thus, the net power output is more appropriate as the performance index than the thermal efficiency of the process [18]. The net power output $P_{\text {net }}$ is calculated as:

$$
f_{1}=P_{\mathrm{net}}=\left|P_{\mathrm{T}}\right|-\left|P_{\mathrm{P}}\right|=\dot{m}_{\mathrm{wf}} \cdot\left(\eta_{\mathrm{s}, \mathrm{T}} \cdot\left|h_{4, \mathrm{~s}}-h_{3}\right|-\eta_{\mathrm{s}, \mathrm{P}}^{-1} \cdot\left|h_{2, \mathrm{~s}}-h_{1}\right|\right),
$$

where $\dot{m}_{\mathrm{wf}}$ denotes the mass flow rate of the working fluid. The power output of the turbine $P_{\mathrm{T}}$ is calculated from an isentropic expansion in the turbine 
considering the constant isentropic turbine efficiency $\eta_{\mathrm{s}, \mathrm{T}}$ and the isentropic structures fulfilling the constituting equations. The number of feasible molecular structures is obtained by solving repeatedly a feasibility problem using the CAMD constraints only and integer cuts to exclude previous solutions.

where $p$ denotes the absolute pressure and $p^{\text {crit }}$ denotes the critical pressure of the working fluid. We prefer reduced pressures as process variables instead of absolute pressures as reduced pressures allow easy bound constraints to ensure only subcritical processes (here: $p^{\text {red }}<0.8$ ). This leads to more stable computations. Pressure drops in evaporator and condenser are neglected in this case study $\left(p_{2}=p_{3}=p_{\text {evap }}\right.$ and $\left.p_{1}=p_{4}=p_{\text {cond }}\right)$. Feasible heat transfer is ensured by constraining the minimum approach temperature $\Delta T_{\min }$ in the heat exchangers. Additionally, the absolute pressure levels of the cycle are constrained to minimal and maximal absolute pressures $p_{\min }$ and $p_{\max }$. Furthermore, the minimal and maximal reduced pressures $p_{\min }^{\mathrm{red}}$ and $p_{\max }^{\mathrm{red}}$ are also determined to constrain the reduced pressures. Feasible cooling in the condenser is ensured by a minimal allowed temperature $T_{\text {cond }}^{\mathrm{min}}$. The size of the designed molecular structures is limited by a maximal number of functional groups (i.e., $\left.{ }_{300} \sum_{i} n_{i} \leq n_{\max }=25\right)$. This corresponds to 9,411 structurally feasible molecular 


\begin{tabular}{lcc} 
Table 1: Specifications of the ORC based on Heberle and Brüggemann \\
\hline Parameter & Symbol & Value \\
\hline Flow rate (heat carrier) & $\dot{m}_{\mathrm{HC}}$ & $66 \mathrm{~kg} \mathrm{~s}^{-1}$ \\
Temperature (heat carrier) & $T_{\mathrm{HC}}^{\mathrm{in}}$ & $120^{\circ} \mathrm{C}$ \\
Heat capacity (heat carrier) & $c_{\mathrm{p}, \mathrm{HC}}$ & $4.2 \mathrm{~kJ} \mathrm{~kg}^{-1} \mathrm{~K}^{-1}$ \\
Isentropic turbine efficiency & $\eta_{\mathrm{s}, \mathrm{T}}$ & 0.8 \\
Isentropic pump efficiency & $\eta_{\mathrm{s}, \mathrm{P}}$ & 0.9 \\
Min. approach temperature & $\Delta T_{\min }$ & $10 \mathrm{~K}$ \\
Min. abs. pressure & $p_{\min }$ & $1 \mathrm{bar}$ \\
Min. red. pressure & $p_{\min }^{\mathrm{red}}$ & $10^{-5}$ \\
Max. abs. pressure & $p_{\max }$ & $50 \mathrm{bar}$ \\
Max. red. pressure & $p_{\max }^{\mathrm{red}}$ & 0.8 \\
Min. cooling temperature & $T_{\mathrm{cond}}^{\min }$ & $20^{\circ} \mathrm{C}$ \\
Max. number of groups & $n_{\max }$ & 25 \\
\hline
\end{tabular}

The optimal net power output of the target calculated in the CoMT problem is $P_{\text {net }}=1.84 \mathrm{MW}$. This target would apply for a hypothetical fluid and gives an upper bound on the performance possible for all fluids which can be described by GPC-SAFT. A ranking of the 10 best real working fluids is identified by the 1-stage CoMT-CAMD approach using integer cuts (Table 2). The approach identifies mainly alkanes and alkenes demonstrating the good performance of these families of working fluids. Propane proves to be the best working fluid for this ORC application with $P_{\text {net }}=1.59 \mathrm{MW}$, which is $13.7 \%$ lower than the hypothetical target. Notably, two non-conventional polar working fluids, dimethyl ether and ethyl methyl ether, are identified showing the potential to generate new and promising working fluids. For the sake of completeness, the „ptimal process parameters of the identified working fluids are given in Appendix B.

To validate the resulting ranking, a subset of the molecular structures considered in CAMD is generated and a brute-force process optimization is performed. 
Table 2: Top 10 molecular structures identified by the 1-stage CoMT-CAMD approach with integer cuts for case study 1 , the net power output and the rank (real) from an individual process optimization of 458 validation structures (=composed of less or equal than 10 functional groups).

\begin{tabular}{clcc}
\hline Rank & Name & $P_{\text {net }} /$ MW & Rank (real) \\
\hline- & Target & 1.84 & - \\
1 & Propane & 1.59 & 1 \\
2 & Propene & 1.57 & 2 \\
3 & Dimethyl ether & 1.53 & 8 \\
4 & Isobutane & 1.56 & 3 \\
5 & Isobutene & 1.55 & 5 \\
6 & n-Butane & 1.55 & 4 \\
7 & Neopentane & 1.55 & 6 \\
8 & 1-Butene & 1.54 & 7 \\
9 & 2-Butene & 1.53 & 10 \\
10 & Ethyl methyl ether & 1.53 & 9 \\
\hline
\end{tabular}

The ranking contains only small molecular structure with $\sum_{i} n_{i} \leq n_{\max }=10$. Thus, all molecular structures are generated, which are composed of less or equal than 10 functional groups. This subset of molecular structures, the validation set, contains 458 working fluids. This subset is comparatively small. However, the computational effort to confirm global optimality of the solution using enumerative search is already enormous. Furthermore, we suppose that larger molecular structures show unfavorable properties for power generation at the temperature level of this case study as no large molecules were identified in the 1-stage CoMT-CAMD optimization. Each molecular structure of the validation set is tested by performing an individual process optimization. The resulting real ranking serves as a measure for the quality of the ranking calculated by the 1-stage CoMT-CAMD approach. The approach identifies the top 10 of the global optimal working fluids of the limited search space nearly in the correct order. Thus, the local solver seems to perform well but integer cuts are required 
to find all good solutions. To evaluate the computation effort, the numbers of function evaluations of the process model are compared: The individual process optimization of the 458 working fluids requires 75,523 function evaluations. Whereas, the 1-stage CoMT-CAMD approach needs 3,188 function evaluations to calculate a ranking of 10 working fluids despite the limited search space for individual process optimization considering only $5 \%$ of the possible fluids. This computation effort corresponds to a saving of $95.8 \%$. The saving increases if all molecular structures would be considered for validation without limiting of the search space. The result shows that the 1-stage CoMT-CAMD approach is accurate and efficient for integrated design of process and working fluid.

The efficient computations allow the extension to multi-objective optimization. For this purpose, a combined heat and power application is considered. For all identified working fluids, the outlet temperature of the heat carrier $T_{\mathrm{HC} \text {,out }}$ is higher than $50^{\circ} \mathrm{C}$. Due to the constraint of the minimal approach temperature in the evaporator, further cooling of the heat carrier reduces the evaporator temperature and, thus, the evaporator pressure. This reduction in turn decreases the thermal efficiency and net power output. Therefore, further cooling of the heat carrier temperature is prevented in the optimization. To further exploit the heat source, the remaining thermal energy of the heat carrier can be used to cover a heat demand.

Generation of combined heat and power (CHP) is favorable for geothermal applications of ORCs [14]. Heberle and Brüggemann [14] show that a connection in series of ORC and heat generation is an efficient CHP concept. For seriallyconnected heat generation, the heat is supplied by the heat carrier after leaving the evaporator of the ORC. The maximal heat supply temperature is thus limited by the ORC outlet temperature of the heat carrier $T_{\mathrm{HC} \text {,out }}$. A rise of the outlet temperature of the heat carrier enhances heat generation, but reduces the ORC heat input and, thus, the net power output of the ORC. To capture the trade-off between heat and power generation, we employ multi-objective optimization within the integrated design of process and working fluid. 
In addition to the net power output $P_{\text {net }}$ (Equation (4)), the ORC outlet temperature of the heat carrier $T_{\mathrm{HC} \text {, out }}$ is considered as second objective function calculated by:

$$
f_{2}=T_{\mathrm{HC}, \text { out }}=T_{\mathrm{HC}, \text { in }}-\frac{\dot{Q}_{\mathrm{ORC}, \text { in }}}{\dot{m}_{\mathrm{HC}} \cdot c_{\mathrm{p}, \mathrm{HC}}}=T_{\mathrm{HC}, \text { in }}-\frac{\dot{m}_{\mathrm{wf}} \cdot\left(h_{3}-h_{2}\right)}{\dot{m}_{\mathrm{HC}} \cdot c_{\mathrm{p}, \mathrm{HC}}},
$$

where $\dot{Q}_{\text {ORC,in }}$ denotes the ORC inlet heat flow calculated from the mass flow rate of the working fluid $\dot{m}_{\mathrm{wf}}$ and the enthalpies $h_{\mathrm{i}}$ at the states 2 and 3 .

The Pareto front is calculated using the normal constraint method [4]. Since we use a local MINLP solver, non-Pareto optimal solutions could be identified. Therefore, the normal constraint method is repeated, where the direction of movement of the normal constraint is changed. Both resulting Pareto fronts are superimposed and filtered according Pareto dominance to increase the accuracy of the solution.

As seen for the single-objective optimization, propane maximizes the net power output (Figure 3). Here, the outlet temperature of the heat carrier is comparatively low $\left(T_{\mathrm{HC} \text {,out }}=58^{\circ} \mathrm{C}\right)$. The polar working fluid acetaldehyde is optimal for low net power output and high outlet temperatures. Depending on the required heating temperature, the working fluid can be selected to maximize the net power output. Overall, 4 working fluids are identified along the Pareto front. Ethylacetylene shows the highest heat carrier outlet temperatures for a wide range of the net power output. Thus, ethylacetylene shows interesting thermodynamic fluid properties for CHP applications as it can cover a wide range of operation conditions. In summer for example, the heat demand is low and the ORC can be operated in a range of high net power output. While during winter time, the heat demand is high and the ORC can be operated in a range of high outlet temperatures of the heat carrier using the same working fluid. The suppliers of ethylacetylene report that it is chemically stable at the thermal conditions of the considered ORC cycle and that isomerization has only to be expected above $200^{\circ} \mathrm{C}[58$. However, ethylacetylene is highly reactive and its applicability as ORC working fluid has to be proved. A closer study reveals that ethyl methyl ether shows a similar performance as ethylacetylene and thus also 


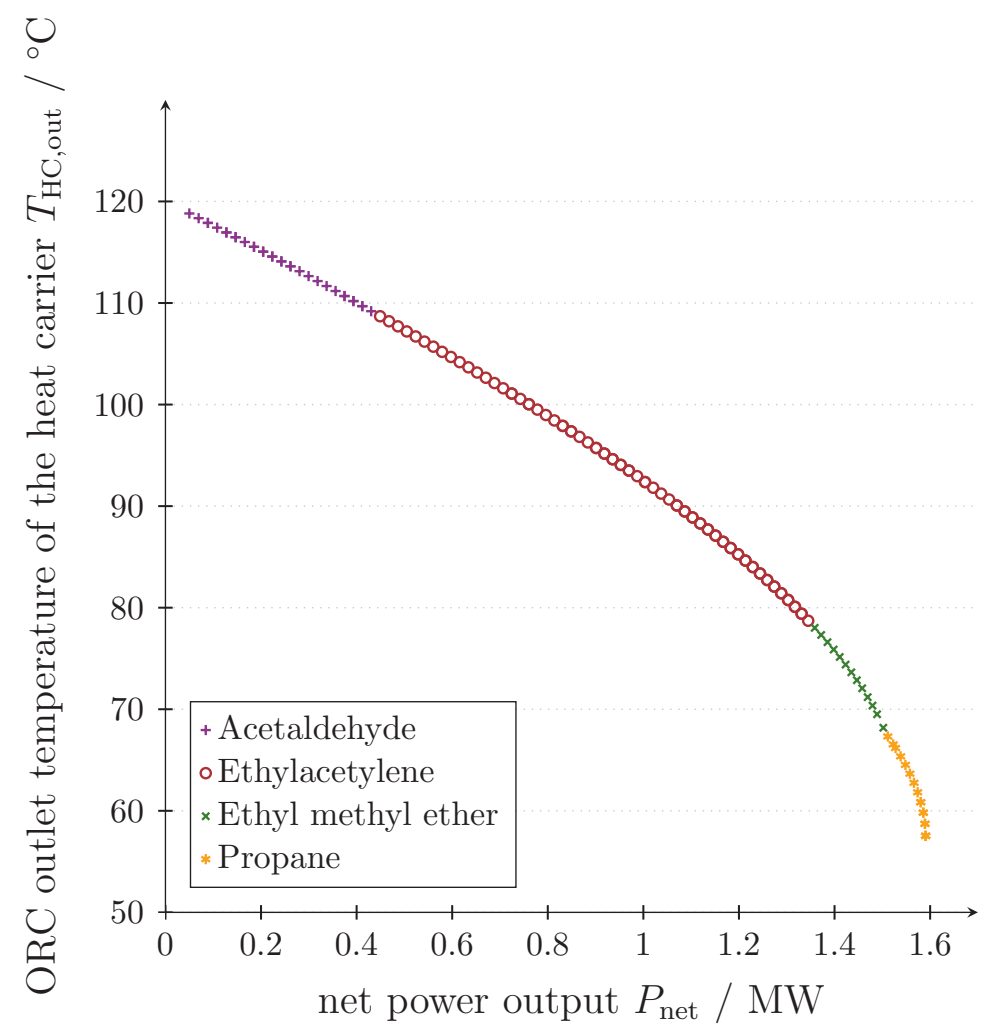

Figure 3: Pareto front for generation of combined heat and power in case study 1, which results from a multi-objective optimization of the net power output $P_{\text {net }}$ versus the ORC outlet temperature of the heat carrier $T_{\mathrm{HC} \text {,out }}$.

interesting thermodynamic fluid properties for CHP applications. The average deviation between the net power output of ethyl methyl ether and ethylacetylene is $0.65 \%$ indicating practically equal performance of the working fluids.

The presented example demonstrates the possibilities and merits of multiobjective optimization within 1-stage CoMT-CAMD.

\subsection{Case study 2: Solarthermal ORC}

The second case study discusses the integrated design of process and working fluid of a subcritical, solarthermal ORC application with regenerator based on Casati et al. [57] (Figure 47). The working fluid is directly heated and evaporated 

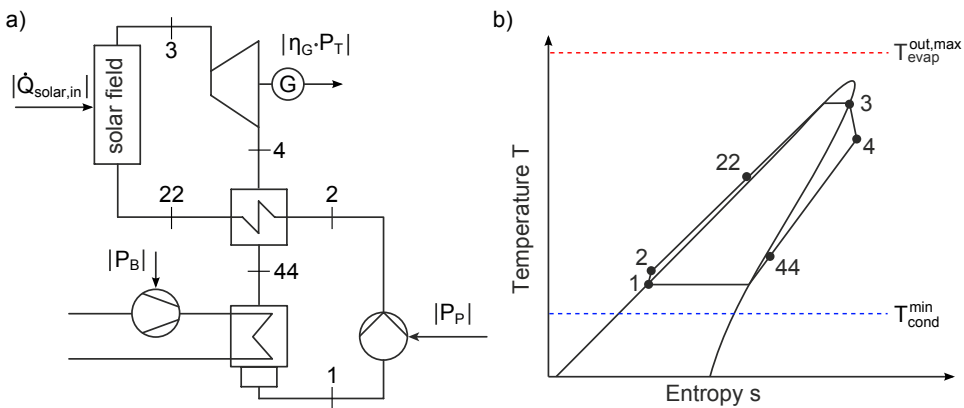

Figure 4: ORC process of case study 2 in (a) flowsheet and (b) temperature-entropy diagram.

in the solar field composed of parabolic troughs. The fixed solarthermal heat input $\dot{Q}_{\text {solar,in }}$ can heat the working fluid up to a temperature limit of $T_{\text {evap }}^{\text {out,max }}=$ $380^{\circ} \mathrm{C}$ (Table 3). Most commonly, constant isentropic turbine efficiencies are assumed during working fluid design, i.e., all working fluids achieve the same performance in the turbine. To capture the impact of the working fluid, we include a detailed model of a one-stage radial inflow turbine in the process model recently developed by Lampe et al. [56] for the two-stage CoMT-CAMD approach. The turbine model enables the preliminary design of the turbine. The isentropic efficiency of the turbine $\eta_{\mathrm{s}, \mathrm{T}}$ is calculated within the model depending on both the process parameters and working fluid properties. Additionally, the detailed turbine model constrains crucial turbine design parameters to ensure that the turbine can actually be built for the considered working fluid and process parameters. A detailed description of the equations of the model is given in Appendix C. More details on the combined design of working fluids, process and turbine will be presented elsewhere [59] (in preparation).

For solarthermal ORC systems, thermal efficiency is an appropriate performance index [18] and is considered as objective function here. Since condensation is enabled by an air-cooling system, the effort of the blower $P_{\mathrm{B}}$ is regarded in the thermal efficiency $\eta_{\text {th }}$ calculated by:

$$
f_{1}=\eta_{\mathrm{th}}=\frac{P_{\text {net }}}{\dot{Q}_{\text {solar,in }}}=\frac{\left|\eta_{\mathrm{G}} \cdot P_{\mathrm{T}}\right|-\left|P_{\mathrm{P}}\right|-\left|P_{\mathrm{B}}\right|}{\dot{Q}_{\text {solar,in }}},
$$

where $\eta_{\mathrm{G}}$ denotes the efficiency of the generator. 
Table 3: Specifications of the ORC based on Casati et al. [57] and Lampe et al. [56].

\begin{tabular}{lcc}
\hline Parameter & Symbol & Value \\
\hline Transferred heat & $\dot{Q}_{\text {solar,in }}$ & $463 \mathrm{~kW}$ \\
Max. temperature at outlet & $T_{\text {evap }}^{\text {out,max }}$ & $380^{\circ} \mathrm{C}$ \\
Generator efficiency & $\eta_{\mathrm{G}}$ & 0.95 \\
Mechanical pump efficiency & $\eta_{\text {mech,P }}$ & 0.9 \\
Isentropic pump efficiency & $\eta_{\mathrm{s}, \mathrm{P}}$ & 0.7 \\
Min. approach temperature & $\Delta T_{\min }$ & $10 \mathrm{~K}$ \\
Min. abs. pressure & $p_{\min }$ & $0.05 \mathrm{bar}$ \\
Min. red. pressure & $p_{\min }^{\text {red }}$ & $10^{-5}$ \\
Max. abs. pressure & $p_{\max }$ & $30 \mathrm{bar}$ \\
Max. red. pressure & $p_{\max }^{\text {red }}$ & 0.8 \\
Min. temperature & $T_{\text {cond }}^{\min }$ & $80^{\circ} \mathrm{C}$ \\
Max. number of groups & $n_{\max }$ & 25 \\
\hline Max. Mach number & $M a c h_{\max }$ & 0.9 \\
Min. blade height & $b_{2, \min }$ & $0.1 \mathrm{~mm}$ \\
Max revolutions per minute & $R P M_{\max }$ & 70,000 \\
Max. expansion ratio & $S V R_{\max }$ & 150 \\
\hline
\end{tabular}

The process variables $x=\left(\dot{m}_{\mathrm{wf}}, p_{\text {cond }}^{\mathrm{red}}, p_{\text {evap }}^{\mathrm{red}}, \Delta T_{\mathrm{sh}}\right)^{\mathrm{T}}$ are: the mass flow rate 415 of the working fluid $\dot{m}_{\mathrm{wf}}$, the reduced operating pressures at condenser outlet $p_{\text {cond }}^{\text {red }}$ and evaporator outlet $p_{\text {evap }}^{\text {red }}$, and the degree of superheating at turbine inlet $\Delta T_{\mathrm{sh}}$. Here, fixed pressure drops are considered in the solar field, the regenerator and the air-side of the condenser based on Casati et al. [57]. Again, the minimum approach temperature, the absolute and reduced, minimal and maximal pressure levels, the minimal cooling temperature and the maximal segment number are specified. The detailed model of the turbine constrains the following design and operating parameters of the turbine: the Mach number Mach, the revolutions per minute $R P M$, the blade height $b_{2}$ and the expansion ratio $S V R$. 
The working fluids identified by 1-stage CoMT-CAMD are given in Ta-

\section{Discussion}

The 1-stage CoMT-CAMD approach enables us to identify the optimal working fluid and the corresponding optimal process parameters in one single optimization problem. Additional integer cuts can be used to generate a ranked list of working fluid candidates. The 1-stage CoMT-CAMD approach can efficiently identify the most promising working fluids from existing databases but goes beyond by also generating new and promising molecular structures. The process 
Table 4: Top 10 molecular structures identified by the 1-stage CoMT-CAMD approach with integer cuts for case study 2 , the net power output and the rank (real) from an individual process optimization of 458 validation structures (=composed of less or equal than 10 functional groups).

\begin{tabular}{clcc}
\hline Rank & Name & $\eta_{\text {th }} / \%$ & Rank (real) \\
\hline- & Target & 26.02 & - \\
1 & Ethyl cyclohexane & 25.57 & 1 \\
2 & Dimethyl cyclohexane & 25.44 & 2 \\
3 & 1,2,3,4-tetramethyl cyclopentane & 25.29 & 3 \\
4 & Ethyl benzene & 25.18 & 7 \\
5 & Xylene & 25.15 & 10 \\
6 & $3,3,4,4-$ Tetramethyl pent-1-ene & 25.14 & 11 \\
7 & Isopropyl cyclopentane & 25.23 & 4 \\
8 & Ethyl methyl cyclopentane & 25.18 & 6 \\
9 & $3,3,4,4-$ tetramethyl pent-1-yne & 25.16 & 8 \\
10 & Trimethyl cyclohexane & 25.16 & 9 \\
\hline
\end{tabular}

model enables capturing all process-related trade-offs in a multi-objective optimization. It is shown that an extension of the process model by a detailed

model of the process components, e.g., the turbine, is possible. Thereby, additional constraints on crucial design parameters can be used to increase practical relevance of the solution.

\subsection{Non-thermodynamic fluid properties}

In the presented work, we consider only thermodynamic equilibrium properties of the working fluid. Additional crucial working fluid properties are neglected, e.g., GWP, flammability, toxicity or thermal stability. Also, the ozone depletion potential (ODP) of the working fluids has to be considered for halogenated working fluids. If $\mathrm{GC}$ approaches are available, the non-thermodynamic fluid properties can be directly integrated into the CAMD formulation as, e.g., by Papadopoulos et al. 21. If no predictive methods based on $\mathrm{GC}$ approaches 
exist, the resulting ranking has to be assessed a posteriori. A posteriori assessment of the ranking allows capturing trade-offs. In this work, highly flammable working fluids are identified in both case studies. Thus, flammable working fluids show high performance. However, the investment costs of flammable working fluids are higher to ensure safety. This trade-off can be captured in an a posteriori assessment.

\subsection{Uncertainties of the $G C$ approach}

GC approaches introduce uncertainties in the result, since the GC-calculated pure component parameters differ from pure component parameters individu-

475 ally adjusted to measurement data, in the following referred to as 'fitted pure component parameters'. These uncertainties can have a large impact on the performance 22]. Lampe et al. 31] show that small deviations in the pure component parameters of PC-SAFT can have a significant impact, as the slope and curvature of the objective function vary strongly. To evaluate the uncertainties due to the GC approach, an individual process optimization is performed for the identified working fluids of both case studies considering the fitted pure component parameters of the working fluids if available. Thereby, isomers of the identified molecular structure are individually regarded if fitted pure component parameters are available. Isomers cannot be resolved by the employed first-order GC approach. The result is compared to the objective function value with GC-calculated parameters (Figure 5p. Isomers are shown by more than one dot for one rank.

The average error in the objective is $0.8 \%$. The GC-calculated pure component parameters underestimate the performance for most of the identified working fluids in both case studies. The identified working fluids are composed of similar groups, so that the uncertainties of the GC approach results in a systematic deviation of the objective function. Overall, the GC approach is suitable to estimate the pure component parameters of PC-SAFT within the integrated design of process and working fluid using the 1-stage CoMT-CAMD approach. Since a list of candidates should be the output, the 1-stage CoMT- 

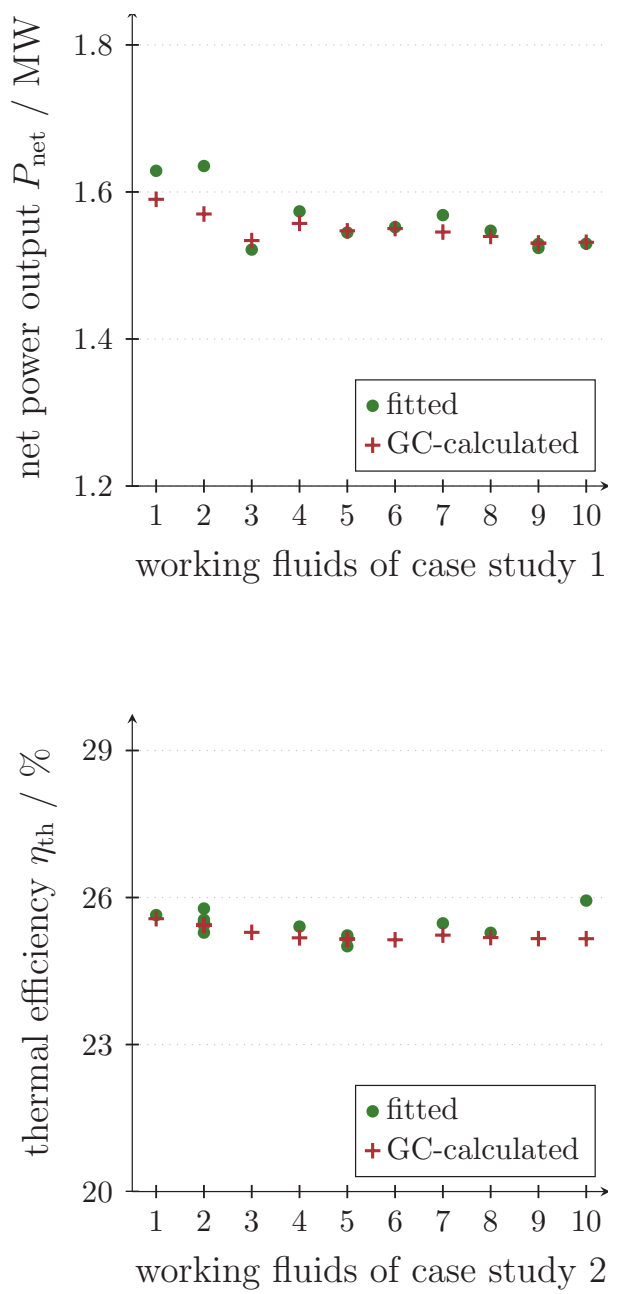

Figure 5: Net power output of the Top 10 identified working fluids of case study 1 (top) and thermal efficiency of the Top 10 identified working fluids of case study 2 (bottom) computed with GC-calculated and fitted pure component parameters. Note that the y-axis is zoomed into the range containing the top candidates for better visualization of the differences. 
CAMD approach allows for efficient and accurate generation of this list. As improved versions of the GC approach become available, they can be readily integrated.

Isomers could be captured within the optimization using a $\mathrm{GC}$ approach of higher order. Such an approach increases the number of integer variables and, thus, the computation effort. In both case studies, all isomeric members show small differences in the objective, with average differences of less than $0.4 \%$. Thus, the efficient first-order GC approach based on PC-SAFT is sufficient to predict isomers by the same molecular structure. The isomers can still be distinguished in the a posteriori assessment of the ranking.

\subsection{Comparison to the two-stage CoMT-CAMD approach}

The presented 1-stage CoMT-CAMD approach builds upon the two-stage CoMT-CAMD approach presented by Lampe et al. [1. In order to compare both approaches, the two-stage CoMT-CAMD approach is applied to case study 1 . In the two-stage CoMT-CAMD approach, a second degree Taylor approximation function $P_{\text {net,ap }}$ of the objective function and a first degree Taylor approximation of the inactive set of constraints are used in the MIQP problem of the structure-mapping (see Section 1). The results of both approaches are compared in Table 5. In addition, the value of the approximation function $P_{\text {net,ap }}$ of the two-stage CoMT-CAMD is also shown for the working fluids identified by 1 -stage CoMT-CAMD and the value of a process optimization $P_{\text {net }}$ is shown for the working fluids identified by the two-stage CoMT-CAMD approach. The values of $P_{\text {net }}$ and $P_{\text {net,ap }}$ are calculated using GC-predicted pure component parameters. As in Section 3 , the results are compared to an individual process

${ }_{520}$ optimization of the 458 generated validation structures consisting of compounds of less or equal than 10 functional groups. The rank of the resulting real ranking is shown in column Rank (real).

The two-stage CoMT-CAMD approach identifies 7 working fluids of the Top 10. The identified working fluids are mostly overestimated by the approximation function. Especially, acetaldehyde and ethane are heavily overestimated and 
Table 5: Comparison of the Top 10 working fluids of case study 1 identified by the 1 -stage CoMT-CAMD approach and the two-stage CoMT-CAMD approach: Objective function value of a process optimization $P_{\text {net }}$, the value of the approximation function $P_{\text {net,ap }}$ and the real rank resulting from an individual process optimization considering a reduces parameter space.

\begin{tabular}{|c|c|c|c|c|c|c|c|c|c|}
\hline \multicolumn{5}{|c|}{ 1-stage CoMT-CAMD } & \multicolumn{5}{|c|}{ two-stage CoMT-CAMD } \\
\hline Rank & Name & $\begin{array}{l}P_{\text {net }} \\
\mathrm{MW}\end{array}$ & $\begin{array}{c}P_{\text {net,ap }} \\
\text { MW }\end{array}$ & $\begin{array}{l}\text { Rank } \\
\text { (real) } \\
\end{array}$ & Rank & Name & $\begin{array}{c}P_{\text {net,ap }} \\
\mathrm{MW}\end{array}$ & $\begin{array}{l}P_{\text {net }} \\
\text { MW }\end{array}$ & $\begin{array}{l}\text { Rank } \\
\text { (real) } \\
\end{array}$ \\
\hline 1 & Propane & 1.59 & 1.58 & 1 & 1 & Acetaldehyde & 2.33 & 1.24 & 15 \\
\hline 2 & Propene & 1.57 & 1.57 & 2 & 2 & 2-Butene & 2.22 & 1.53 & 10 \\
\hline 3 & Dimethyl ether & 1.53 & 1.72 & 7 & 3 & Isobutene & 2.19 & 1.55 & 5 \\
\hline 4 & Isobutane & 1.56 & 1.83 & 3 & 4 & Ethane & 2.17 & 0.97 & 24 \\
\hline 5 & Isobutene & 1.55 & 2.19 & 5 & 5 & n-Butane & 2.01 & 1.55 & 4 \\
\hline 6 & n-Butane & 1.55 & 2.01 & 4 & 6 & 1-Butene & 1.88 & 1.54 & 7 \\
\hline 7 & Neopentane & 1.55 & 2.38 & 6 & 7 & Isobutane & 1.83 & 1.56 & 3 \\
\hline 8 & 1-Butene & 1.54 & 1.88 & 7 & 8 & Dimethyl ether & 1.72 & 1.53 & 8 \\
\hline 9 & 2-Butene & 1.53 & 2.22 & 10 & 9 & Propyne & 1.59 & 1.52 & 12 \\
\hline 10 & Ethyl methyl ether & 1.53 & 2.89 & 9 & 10 & Propane & 1.59 & 1.58 & 1 \\
\hline
\end{tabular}


thus mis-classified. Neopentane and ethyl methyl ester, which are identified by 1-stage CoMT-CAMD, show a high approximation function value, but they are excluded by the linear approximation of the constraints and thus not identified by the two-stage CoMT-CAMD approach. The presented 1-stage CoMT-CAMD approach thus improves the already good result of the two-stage CoMT-CAMD approach. The working fluids are classified more accurately and no working fluid is excluded by a coarse approximation of the constraints. The adaptive strategy for refinement of the approximation pursued by the outer-approximation strategy proves useful to improve the classification of the identified working fluids.

\section{Conclusions}

In this work, we present a one-stage approach for the integrated design of ORC process and working fluid, so-called 1-stage CoMT-CAMD. The approach identifies the optimal working fluid and the corresponding optimal process parameters in one single MINLP optimization problem using the modern PCSAFT EoS to model the working fluid. Computational efficiency allows for a single-objective optimization and even allows for a multi-objective optimization.

1-stage CoMT-CAMD builds upon the two-stage CoMT-CAMD approach presented by Lampe et al. [1. A detailed process model and a detailed fluid model are combined to capture all thermodynamic trade-offs. The process model is based on equilibrium thermodynamics depending on both process variables and thermodynamic properties of the working fluid. The fluid properties are calculated in a thermodynamically consistent way using the PC-SAFT equation of state. A CAMD formulation in combination with a GC approach for PC-SAFT is used to integrate the fluid design as degree of freedom within the optimization.

The considered molecular families of the GC approach are: alkanes, alkenes, 1alkynes, cyclic components with alkyl side groups, aldehydes, ketones, ethers, formats and esters. The resulting MINLP problem can be solved considering one or multiple process-related objective functions to capture all process-based 
trade-offs. Here, we use the deterministic local MINLP solver DICOPT, which support with the development of the detailed turbine model. 


\section{References}

\section{References}

${ }_{585}$ [1] M. Lampe, M. Stavrou, J. Schilling, E. Sauer, J. Gross, A. Bardow, Computer-aided molecular design in the continuous-molecular targeting framework using group-contribution PC-SAFT, Comput. Chem. Eng. 81 (2015) 278-287.

[2] C. S. Adjiman, A. Galindo, G. Jackson, Molecules matter: the expanding envelope of process design, in: M. R. Eden (Ed.), Proceedings of the 8th International Conference on Foundations of Computer-Aided Process Design, Vol. 34 of Comput. aided Chem. Eng., Elsevier, Amsterdam, 2014, pp. 55-64.

[3] A. Bardow, K. Steur, J. Gross, Continuous-Molecular Targeting for Integrated Solvent and Process Design, Ind. Eng. Chem. Res. 49 (6) (2010) $2834-2840$.

[4] J. Burger, V. Papaioannou, S. Gopinath, G. Jackson, A. Galindo, C. S. Adjiman, A hierarchical method to integrated solvent and process design of physical $\mathrm{CO}_{2}$ absorption using the SAFT- $\gamma$ Mie approach, AIChE J. 61 (10) (2015) 3249-3269.

[5] A. I. Papadopoulos, P. Linke, Integrated solvent and process selection for separation and reactive separation systems, Chem. Eng. Process. 48 (5) (2009) 1047-1060.

[6] M. Stavrou, M. Lampe, A. Bardow, J. Gross, Continuous Molecular Targeting-Computer-Aided Molecular Design (CoMT-CAMD) for Simultaneous Process and Solvent Design for $\mathrm{CO}_{2}$ Capture, Ind. Eng. Chem. Res. 53 (46) (2014) 18029-18041.

[7] T. Zhou, Z. Lyu, Z. Qi, K. Sundmacher, Robust design of optimal solvents for chemical reactions - A combined experimental and computational strategy, Chem. Eng. Sci. 137 (2015) 613-625. 
[8] D. Roskosch, B. Atakan, Reverse engineering of fluid selection for thermodynamic cycles with cubic equations of state, using a compression heat pump as example, Energy 81 (2015) 202-212.

[9] A. P. Samudra, N. V. Sahinidis, Optimization-based framework for computer-aided molecular design, AIChE J. 59 (10) (2013) 3686-3701.

[10] E. L. First, M. M. F. Hasan, C. A. Floudas, Discovery of novel zeolites for natural gas purification through combined material screening and process optimization, AIChE J. 60 (5) (2014) 1767-1785.

[11] P. Linke, A. Papadopoulos, P. Seferlis, Systematic Methods for Working Fluid Selection and the Design, Integration and Control of Organic Rankine Cycles-A Review, Energies 8 (6) (2015) 4755-4801.

[12] P. Colonna, E. Casati, C. Trapp, T. Mathijssen, J. Larjola, T. TurunenSaaresti, A. Uusitalo, Organic Rankine Cycle Power Systems: From the Concept to Current Technology, Applications, and an Outlook to the Future, J. Eng. Gas Turbines Power 137 (10) (2015) 100801.

[13] B. F. Tchanche, G. Papadakis, G. Lambrinos, A. Frangoudakis, Fluid selection for a low-temperature solar organic Rankine cycle, Appl. Therm. Eng. 29 (11-12) (2009) 2468-2476.

[14] F. Heberle, D. Brüggemann, Exergy based fluid selection for a geothermal Organic Rankine Cycle for combined heat and power generation, Appl. Therm. Eng. 30 (11-12) (2010) 1326-1332.

[15] U. Drescher, D. Brüggemann, Fluid selection for the Organic Rankine Cycle (ORC) in biomass power and heat plants, Appl. Therm. Eng. 27 (1) (2007) $223-228$.

${ }_{635}$ [16] Z. Q. Wang, N. J. Zhou, J. Guo, X. Y. Wang, Fluid selection and parametric optimization of organic Rankine cycle using low temperature waste heat, Energy 40 (1) (2012) 107-115. 
[17] E. H. Wang, H. G. Zhang, B. Y. Fan, M. G. Ouyang, Y. Zhao, Q. H. Mu, Study of working fluid selection of organic Rankine cycle (ORC) for engine waste heat recovery, Energy 36 (5) (2011) 3406-3418.

[18] J. Bao, L. Zhao, A review of working fluid and expander selections for organic Rankine cycle, Renew. Sust. Energ. Rev. 24 (2013) 325-342.

[19] S. Quoilin, M. D. van Broek, S. Declaye, P. Dewallef, V. Lemort, Technoeconomic survey of Organic Rankine Cycle (ORC) systems, Renew. Sust. Energ. Rev. 22 (2013) 168-186.

[20] R. Gani, Chemical product design: Challenges and opportunities, Comput. Chem. Eng. 28 (12) (2004) 2441-2457.

[21] A. I. Papadopoulos, M. Stijepovic, P. Linke, On the systematic design and selection of optimal working fluids for Organic Rankine Cycles, Appl. Therm. Eng. 30 (6-7) (2010) 760-769.

[22] A. I. Papadopoulos, M. Stijepovic, P. Linke, P. Seferlis, S. Voutetakis, Toward Optimum Working Fluid Mixtures for Organic Rankine Cycles using Molecular Design and Sensitivity Analysis, Ind. Eng. Chem. Res. 52 (34) (2013) 12116-12133.

[23] O. Palma-Flores, A. Flores-Tlacuahuac, G. Canseco-Melchor, Optimal molecular design of working fluids for sustainable low-temperature energy recovery, Comput. Chem. Eng. 72 (2014) 334-349.

[24] E. C. Marcoulaki, A. C. Kokossis, On the development of novel chemicals using a systematic optimisation approach. Part II. Solvent design, Chem. Eng. Sci. 55 (13) (2000) 2547-2561.

[25] R. Gani, Case studies in chemical product design - use of CAMD techniques, in: K. M. Ng (Ed.), Chemical product design, Vol. 23 of Comput. Aided Chem. Eng., Elsevier, Amsterdam, 2007, pp. 435-458. 
[26] R. Vaidyanathan, M. El-Halwagi, Computer-Aided Design of High Performance Polymers, J. Elastom. Plast. 26 (3) (1994) 277-293.

[27] N. V. Sahinidis, M. Tawarmalani, M. Yu, Design of alternative refrigerants via global optimization, AIChE J. 49 (7) (2003) 1761-1775.

[28] L. Y. Ng, F. K. Chong, N. G. Chemmangattuvalappil, Challenges and opportunities in computer-aided molecular design, Comput. Chem. Eng. 81 (2015) 115-129.

[29] M. Eden, S. Jørgensen, R. Gani, M. El-Halwagi, A novel framework for simultaneous separation process and product design, Chem. Eng. Process. 43 (5) (2004) 595-608.

[30] J. Gross, G. Sadowski, Perturbed-Chain SAFT: An Equation of State Based on a Perturbation Theory for Chain Molecules, Ind. Eng. Chem. Res. 40 (4) (2001) 1244-1260.

[31] M. Lampe, M. Stavrou, H. M. Bücker, J. Gross, A. Bardow, Simultaneous Optimization of Working Fluid and Process for Organic Rankine Cycles Using PC-SAFT, Ind. Eng. Chem. Res. 53 (21) (2014) 8821-8830.

${ }_{680}^{6}[32]$ J. Schilling, M. Lampe, J. Gross, A. Bardow, Working Fluid Selection for Organic Rankine Cycles based on Continuous-Molecular Targets, in: University of Liège and Ghent University (Ed.), ASME-ORC2015, Vol. 1, 2015, pp. 732-741, (visited on: 2015-11-30).

n URL http://www.asme-orc2015.be/online/proceedings/documents/ 75.pdf

[33] E. Sauer, M. Stavrou, J. Gross, Comparison between a Homo- and a Heterosegmented Group Contribution Approach Based on the PerturbedChain Polar Statistical Associating Fluid Theory Equation of State, Ind. Eng. Chem. Res. 53 (38) (2014) 14854-14864.

[34] F. E. Pereira, E. Keskes, A. Galindo, G. Jackson, C. S. Adjiman, Integrated solvent and process design using a SAFT-VR thermodynamic description: 
High-pressure separation of carbon dioxide and methane, Comput. Chem. Eng. 35 (3) (2011) 474-491.

[35] T. Zhou, K. McBride, X. Zhang, Z. Qi, K. Sundmacher, Integrated solvent and process design exemplified for a Diels-Alder reaction, AIChE J. 61 (1) (2015) 147-158.

[36] J. Schilling, M. Lampe, J. Gross, A. Bardow, One-stage approach for the integrated design of ORC processes and working fluid using PC-SAFT, in: Z. Kravanja (Ed.), Proceedings of the 26th European Symposium on Computer Aided Process Engineering, Elsevier, Amsterdam, 2016, (accepted).

[37] O. Lötgering-Lin, J. Gross, Group Contribution Method for Viscosities Based on Entropy Scaling Using the Perturbed-Chain Polar Statistical Associating Fluid Theory, Ind. Eng. Chem. Res. 54 (32) (2015) 7942-7952.

[38] L. T. Novak, Fluid Viscosity-Residual Entropy Correlation, Int. J. Chem. React. Eng. 9 (1) (2011) A107.

[39] H. Struebing, Identifying optimal solvents for reactions using quantum mechanics and computer-aided molecular design, $\mathrm{PhD}$ thesis, Imperial College London, London (2011).

[40] H. Struebing, C. S. Adjiman, A. and Galindo, Optimal solvent design for reactions using computer-aided molecular design, (visited on: 2015-11-30) (2011).

10 URL http://www.minlp.org/library/problem/mod/index.php?lib= MINLP\& $i=180 \& p i=-137$

[41] M. A. Duran, I. E. Grossmann, An outer-approximation algorithm for a class of mixed-integer nonlinear programs, Mathematical Programming 36 (3) (1986) 307-339.

[42] C. A. Floudas, Nonlinear and mixed-integer optimization: Fundamentals and applications, Topics in chemical engineering, Oxford University Press, New York, 1995. 
720

[43] R. E. Rosenthal, GAMS - A User's Guide, GAMS Release 24.6.1, (visited on: 2016-03-08) (2016). URL http://www.gams.com/help/topic/gams.doc/userguides/ GAMSUsersGuide.pdf

[44] G. R. Kocis, I. E. Grossmann, Computational experience with DICOPT

[48] Y. Y. Haimes, L. S. Lasdon, D. A. Wismer, On a Bicriterion Formulation of the Problems of Integrated System Identification and System Optimization, IEEE Trans. Syst., Man, Cybern., Syst. 1 (3) (1971) 296-297.

[49] M. Bortz, J. Burger, N. Asprion, S. Blagov, R. Böttcher, U. Nowak,

[51] J. Gross, J. Vrabec, An equation-of-state contribution for polar components: Dipolar molecules, AIChE J. 52 (3) (2006) 1194-1204. 
[52] K. G. Joback, R. C. Reid, Estimation of pure-component properties from group-contributions, Chem. Eng. Commun. 57 (1-6) (1987) 233-243.

[53] J. Vijande, M. M. Piñeiro, D. Bessières, H. Saint-Guirons, J. L. Legido, Description of PVT behaviour of hydrofluoroethers using the PC-SAFT EOS, Phys. Chem. Chem. Phys. 6 (4) (2004) 766-770.

[54] L. F. Vega, G. Jackson, 20 Years of the SAFT equation of state - Recent advances and challenges, Fluid Phase Equilibria 306 (1) (2011) 1-3.

[55] M. D. Stuber, J. K. Scott, P. I. Barton, Convex and concave relaxations of implicit functions, Optim. Method. Softw. 30 (3) (2014) 424-460.

[56] M. Lampe, J. Gross, P. Colonna, A. Bardow, Integrated Design of Working Fluid, Process and Turbine of Organic Rankine Cycles using PC-SAFT, in: M.-O. Bertran, T. Bisgaard, R. Frauzem (Eds.), Book of abstracts / 12th International Symposium on Process Systems Engineering and 25th European Symposium on Computer Aided Process Engineering, Vol. 727 of EFCE event, Technical University of Denmark (DTU) Department of Chemical and Biochemical Engineering, Lyngby, 2015, p. 145.

[57] E. Casati, P. Colonna, N. R. Nannan, Supercritical ORC turbogenerators coupled with linear solar collectors, in: Proceedings of the ISES solar world congress 2011, Vol. 5, 2011, pp. 4056-4068.

[58] MEGS Specialty Gases and Equipment, Product information: Ethyl acetylene, (visited on: 2015-11-30) (2002). URL http://www.megs.ca/MSDS/Pdf/Ethyl_Acetylene.PDF

[59] M. Lampe, C. de Servi, J. Schilling, J. Gross, P. Colonna, A. Bardow, Towards integrated working fluid and turbine design for Organic Rankine Cycles, (manuscript in preparation).

[60] S. L. Dixon, C. A. Hall, Fluid mechanics and thermodynamics of turbomachinery, 7th Edition, Mechanical engineering / Fluid Mechanics, Elsevier, Amsterdam, 2014. 
775

62] D. Fiaschi, G. Manfrida, F. Maraschiello, Thermo-fluid dynamics preliminary design of turbo-expanders for ORC cycles, Appl. Energy 97 (2012) 601-608.

[63] C. Rodgers, R. Geiser, Performance of a High-Efficiency Radial/Axial Turbine, Journal of Turbomachinery 109 (2) (1987) 151. 


\section{Appendix A. Group contribution values}

Appendix A.1. Group contribution values for heat capacity of the ideal gas

The heat capacity of the ideal gas $c_{\mathrm{p}}^{\mathrm{ig}}$ is calculated by Joback's first-order group-contribution method [52]:

$$
c_{\mathrm{p}}^{\mathrm{ig}}=A+B \cdot T+C \cdot T^{2}+D \cdot T^{3},
$$

where $T$ denotes the temperature. The parameters $A, B, C$ and $D$ are calculated from the molecular structure of the working fluid $y^{\mathrm{S}}=\left(n_{1}, n_{2}, \ldots n_{\mathrm{m}}\right)^{\mathrm{T}}$ by:

$$
\begin{aligned}
A & =\sum_{i \in I} n_{i} \cdot A_{i}-37.93 \frac{\mathrm{J}}{\mathrm{mol} \mathrm{K}}, \\
B & =\sum_{i \in I} n_{i} \cdot B_{i}+0.210 \frac{\mathrm{J}}{\mathrm{mol} \mathrm{K}^{2}}, \\
C & =\sum_{i \in I} n_{i} \cdot C_{i}-3.91 \cdot 10^{-4} \frac{\mathrm{J}}{\mathrm{mol} \mathrm{K}^{3}}, \\
D & =\sum_{i \in I} n_{i} \cdot D_{i}+2.06 \cdot 10^{-7} \frac{\mathrm{J}}{\mathrm{mol} \mathrm{K}^{4}} .
\end{aligned}
$$

The group contribution values $A_{i}, B_{i}, C_{i}$ and $D_{i}$ of groups of type $i$ are given in Table A.6.

Appendix A.2. Group contribution values for GPC-SAFT

The group contribution values for GPC-SAFT used in equation (3) are given 
Table A.6: Group contribution values for the calculation of heat capacity of the ideal gas by Joback's first-order group-contribution method [52].

\begin{tabular}{|c|c|c|c|c|}
\hline Group & $\begin{array}{c}A_{i} \\
\frac{\mathrm{J}}{\mathrm{mol} \mathrm{K}}\end{array}$ & $\begin{array}{c}B_{i} \\
10^{-2} \frac{\mathrm{J}}{\mathrm{mol} \mathrm{K}^{2}}\end{array}$ & $\begin{array}{c}C_{i} \\
10^{-5} \frac{\mathrm{J}}{\mathrm{mol} \mathrm{K}^{3}}\end{array}$ & $\begin{array}{c}D_{i} \\
10^{-8} \frac{\mathrm{J}}{\mathrm{mol} \mathrm{K}^{4}}\end{array}$ \\
\hline$-\mathrm{CH}_{3}$ & 19.5 & -0.808 & 15.3 & -9.67 \\
\hline$-\mathrm{CH}_{2}-$ & -0.909 & 9.50 & -5.44 & 1.19 \\
\hline$>\mathrm{CH}-$ & -23.0 & 20.4 & -26.5 & 12.0 \\
\hline$>\mathrm{C}<$ & -66.2 & 42.7 & -64.1 & 30.1 \\
\hline$=\mathrm{CH}_{2}$ & 23.6 & -3.81 & 17.2 & -10.3 \\
\hline$=\mathrm{CH}-$ & -8.0 & 10.5 & -9.63 & 3.56 \\
\hline$>C=$ & -28.1 & 20.8 & -30.6 & 14.6 \\
\hline$-\mathrm{C} \equiv \mathrm{CH}$ & 32.37 & -0.70 & 10.267 & -6.641 \\
\hline$>\mathrm{C}^{\text {Arom }}=$ & -8.25 & 10.1 & -14.2 & 6.78 \\
\hline $\mathrm{CH}^{\text {Arom }}=$ & -2.14 & 5.74 & -0.164 & -1.59 \\
\hline$>\mathrm{CH}^{\text {Pent }}-$ & -20.5 & 16.2 & -16.0 & 6.24 \\
\hline$/ \mathrm{CH}_{2}^{\mathrm{Pent}}-$ & -6.03 & 8.54 & -0.8 & -1.80 \\
\hline$>\mathrm{CH}^{\mathrm{Hex}}-$ & -20.5 & 16.2 & -16.0 & 6.24 \\
\hline $\mathrm{CH}_{2}^{\mathrm{Hex}}-$ & -6.03 & 8.54 & -0.8 & -1.80 \\
\hline$-\mathrm{CH}=\mathrm{O}$ & 30.9 & -3.36 & 16.0 & -9.88 \\
\hline$>\mathrm{C}=\mathrm{O}$ & 6.45 & 6.70 & -3.57 & 0.286 \\
\hline$-\mathrm{O}-\mathrm{CH}_{3}$ & 45.0 & -7.13 & 26.4 & -15.15 \\
\hline$-\mathrm{O}-\mathrm{CH}_{2}-$ & 24.591 & 3.18 & 5.66 & -4.29 \\
\hline$-\mathrm{O}-\mathrm{CH}=\mathrm{O}$ & 24.1 & 4.27 & 8.04 & -6.87 \\
\hline$-\mathrm{O}-(\mathrm{C}=\mathrm{O})-$ & 24.5 & 4.02 & 4.02 & -4.52 \\
\hline
\end{tabular}


Table A.7: Group contribution values for GPC-SAFT [33].

\begin{tabular}{|c|c|c|c|c|}
\hline Group & $m_{i} /-$ & $\sigma_{i} / \AA$ & $(\epsilon / k)_{i} / \mathrm{K}$ & $\mu_{i} / \mathrm{D}$ \\
\hline$-\mathrm{CH}_{3}$ & $0.611,98$ & $3.720,2$ & 229.9 & 0.0 \\
\hline$-\mathrm{CH}_{2}-$ & $0.456,06$ & 3.89 & 239.01 & 0.0 \\
\hline$>\mathrm{CH}-$ & $0.143,04$ & $4.859,7$ & 349.64 & 0.0 \\
\hline$>\mathrm{C}^{\prime}<$ & $-0.669,7$ & $-1.787,8$ & 107.68 & 0.0 \\
\hline$=\mathrm{CH}_{2}$ & $0.369,39$ & $4.026,4$ & 289.49 & 0.0 \\
\hline$=\mathrm{CH}-$ & $0.563,61$ & $3.551,9$ & 216.69 & 0.0 \\
\hline$>\mathrm{C}=$ & $0.863,67$ & $3.181,5$ & 156.31 & 0.0 \\
\hline$-\mathrm{C} \equiv \mathrm{CH}$ & $1.327,9$ & $2.942,1$ & 223.05 & 0.0 \\
\hline $\mathrm{C}^{\mathrm{Arom}}=$ & $0.153,71$ & $3.962,2$ & 527.2 & 0.0 \\
\hline, $\mathrm{CH}^{\text {Arom }}=$ & $0.423,35$ & 3.727 & 274.41 & 0.0 \\
\hline$>\mathrm{CH}^{\text {Pent }}-$ & $0.033,14$ & $7.719,0$ & $1,297.7$ & 0.0 \\
\hline $\mathrm{CH}_{2}^{\mathrm{Pent}}-$ & $0.467,42$ & $3.727,2$ & 267.16 & 0.0 \\
\hline$>\mathrm{CH}^{\mathrm{Hex}}-$ & $0.028,80$ & $8.977,9$ & $1,306.7$ & 0.0 \\
\hline $\mathrm{CH}_{2}^{\mathrm{Hex}}-$ & $0.394,96$ & $3.912,6$ & 289.03 & 0.0 \\
\hline$-\mathrm{CH}=\mathrm{O}$ & $1.577,4$ & $2.803,5$ & 242.99 & $2.455,6$ \\
\hline$>\mathrm{C}=\mathrm{O}$ & 1.223 & $2.812,4$ & 249.04 & $3.243,2$ \\
\hline$-\mathrm{O}-\mathrm{CH}_{3}$ & $1.653,9$ & $3.069,7$ & 196.05 & $1.386,6$ \\
\hline$-\mathrm{O}-\mathrm{CH}_{2}-$ & $1.134,9$ & $3.203,7$ & 187.13 & 2.744 \\
\hline$-\mathrm{O}-\mathrm{CH}=\mathrm{O}$ & $1.752,5$ & $2.904,3$ & 229.63 & $2.791,6$ \\
\hline$-\mathrm{O}-(\mathrm{C}=\mathrm{O})-$ & $1.506,3$ & $2.816,6$ & 222.52 & $3.165,2$ \\
\hline
\end{tabular}




\section{Appendix B. Optimal process parameters of the identified working} fluids

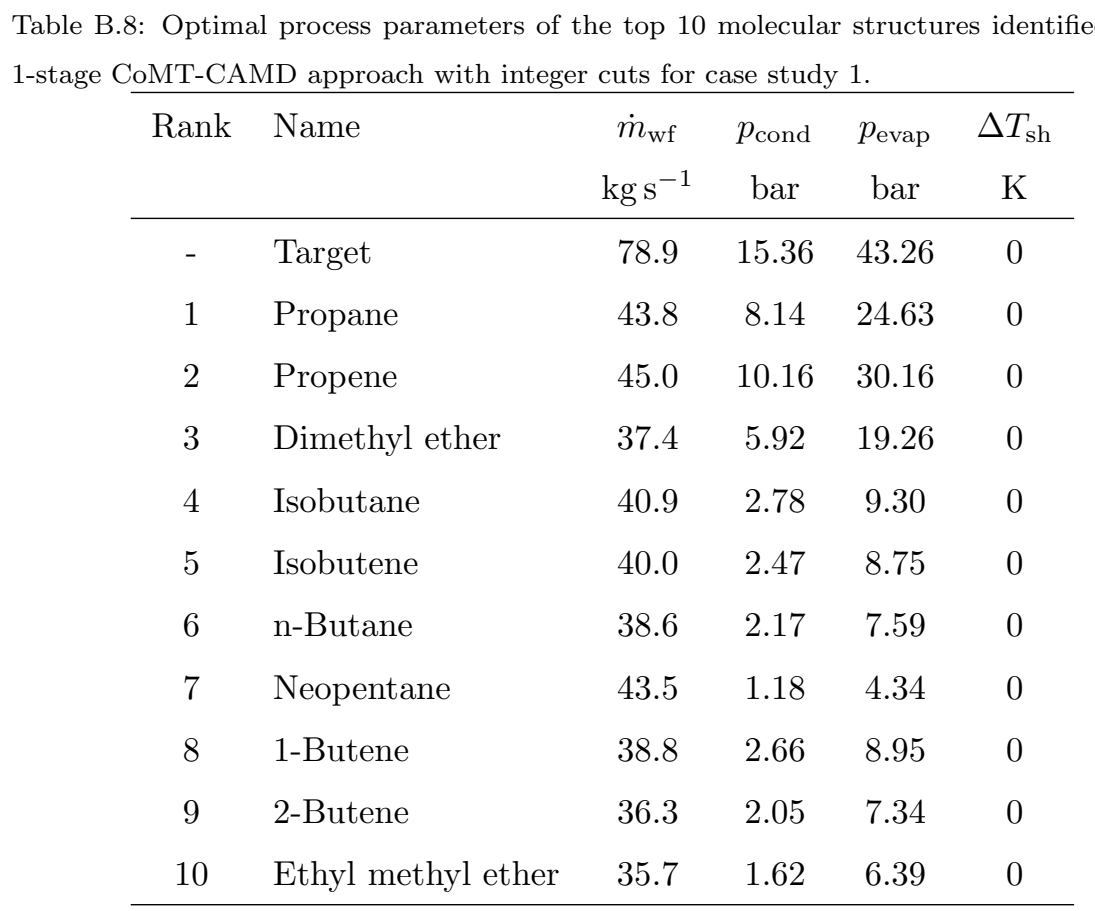


Table B.9: Optimal process parameters of the top 10 molecular structures identified by the 1-stage CoMT-CAMD approach with integer cuts for case study 2.

\begin{tabular}{clcccc}
\hline Rank & Name & $\begin{array}{c}\dot{m}_{\mathrm{wf}} \\
\mathrm{kg} \mathrm{s}^{-1}\end{array}$ & $\begin{array}{c}p_{\text {cond }} \\
\text { bar }\end{array}$ & $\begin{array}{c}p_{\text {evap }} \\
\text { bar }\end{array}$ & $\begin{array}{c}\Delta T_{\text {sh }} \\
\text { K }\end{array}$ \\
\hline- & Target & 0.92 & 0.21 & 29.99 & 41.8 \\
1 & Ethyl cyclohexane & 0.86 & 0.21 & 28.42 & 58.0 \\
2 & Dimethyl cyclohexane & 0.89 & 0.27 & 27.92 & 66.4 \\
3 & 1,2,3,4-tetramethyl cyclopentane & 0.94 & 0.18 & 25.75 & 57.8 \\
4 & Ethyl benzene & 0.80 & 0.17 & 22.63 & 76.6 \\
5 & Xylene & 0.79 & 0.15 & 20.74 & 79.7 \\
6 & 3,3,4,4-Tetramethyl pent-1-ene & 0.98 & 0.25 & 26.33 & 60.6 \\
7 & Isopropyl cyclopentane & 0.86 & 0.24 & 28.63 & 68.2 \\
8 & Ethyl methyl cyclopentane & 0.87 & 0.26 & 28.38 & 71.1 \\
9 & 3,3,4,4-tetramethyl pent-1-yne & 0.93 & 0.20 & 28.25 & 57.3 \\
10 & Trimethyl cyclohexane & 0.93 & 0.14 & 20.92 & 62.7 \\
\hline
\end{tabular}

\section{Appendix C. Equations for the Turbine Model}

In this work, we consider a one-stage radial inflow turbine developed by

Lampe et al. [56. In the following, we use the notation of the states and velocities as defined in Figure C.6. The working fluid enters the nozzel of the turbine in state 1 , the rotor in state 2 and leaves the turbine in state 3 , as the diffuser is neglected. Stagnation states of the working fluid are denoted by 0X, when the working fluid recovers the kinetic energy from state $\mathrm{X}$. The state 3ss corresponds to an isentropic turbine, the state $3 \mathrm{~s}$ to an isentropic rotor and a real nozzel.

The isentropic efficiency of the turbine $\eta_{\mathrm{s}, \mathrm{T}}$ is calculated from loss coefficients for the rotor $\zeta_{\mathrm{R}}$ and nozzel $\zeta_{\mathrm{N}}$ as well as fluid velocities as [60]:

$$
\eta_{\mathrm{s}, \mathrm{T}}=\frac{h_{01}-h_{03}}{h_{01}-h_{3 \mathrm{ss}}}=\frac{\Delta w}{\Delta w+\frac{1}{2}\left(c_{3}^{2}+w_{3}^{2} \zeta_{\mathrm{R}}+c_{2}^{2} \zeta_{\mathrm{N}}\left(\frac{T_{3}}{T_{2}}\right)\right)},
$$



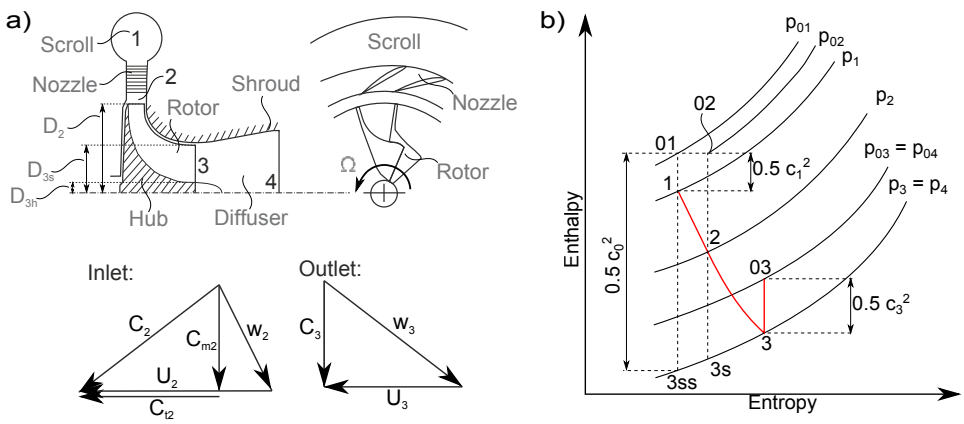

Figure C.6: a) Schematic of the radial turbine as well as the corresponding velocity triangles and b) Enthalpy-entropy diagram of the expansion process in the turbine

where $\Delta w=h_{01}-h_{03}$ denotes the specific work of the turbine. The loss coefficients for the rotor $\zeta_{\mathrm{R}}$ and nozzel $\zeta_{\mathrm{N}}$ are calculated by:

$$
\begin{aligned}
h_{3}-h_{3 \mathrm{~s}} & =\frac{1}{2} w_{3}^{2} \zeta_{\mathrm{R}} \\
h_{3 \mathrm{~s}}-h_{3 \mathrm{ss}} & =\frac{1}{2} c_{2}^{2} \zeta_{\mathrm{N}} \frac{T_{3}}{T_{2}} .
\end{aligned}
$$

We rewrite the isentropic efficiency as an implicit function for turbine efficiency $\eta_{\mathrm{s}, \mathrm{T}}=f\left(p_{01}, T_{1}, p_{3}, y\right)$. Using assumptions for the degree of reaction $R$ 60, 61, 62]:

$$
R=\frac{h_{2}-h_{3}}{h_{1}-h_{3}}=0.15
$$

the exit velocity ratio $\Phi[63$ :

$$
\Phi=\frac{c_{3}}{U_{2}}=0.25
$$

and the blade loading coefficient $\Psi$ :

$$
\Psi=\frac{U_{2}}{C_{0}}=0.7
$$

we can express the velocities in Equation (C.1) in terms of these variables. $c_{2}$ can be expressed as

$$
c_{2}=\sqrt{2\left(h_{02}-h_{2}\right)} .
$$


An energy balance around the nozzle yields $h_{01}=h_{02}$. Using Equation C.4 and neglecting the diffuser (state $3=$ state 4 ) yields

$$
c_{2}=\sqrt{2\left(h_{01}-h_{3}-R\left(h_{1}-h_{3}\right)\right)},
$$

where $h_{01}=h_{1}+\frac{1}{2} C_{1}^{\varkappa^{0}}=\mathrm{h}\left(p_{1}, T_{1}, y\right)$. The enthalpy $\mathrm{h}(p, T, y)$ defined by pressure $p$, temperature $T$ and the pure component parameters $y$ can be calculated using PC-SAFT.

The next velocity in Equation (C.1), $c_{3}$, can be expressed from the definition of $\Phi, \Psi$ (in Equation (C.5) and Equation (C.6), respectively) and the sprouting velocity $C_{0}=\sqrt{2\left(h_{01}-h_{3 s s}\right)}$, which is the artificial velocity corresponding to a kinetic energy equal to the total enthalpy drop of an isentropic turbine

$$
c_{3}=\Phi \Psi C_{0}=\Phi \Psi \sqrt{2\left(h_{01}-h_{3 s s}\right)} .
$$

The relative velocity at the rotor outlet $w_{3}$ can be expressed using the velocity triangle in Figure C.6 as

$$
\begin{aligned}
w_{3} & =\sqrt{U_{3}^{2}+c_{3}^{2}}=\sqrt{\left(U_{2} \frac{D_{3}}{D_{2}}\right)^{2}+c_{3}^{2}} \\
& =\sqrt{\left(\Psi C_{0} \frac{D_{3}}{D_{2}}\right)^{2}+c_{3}^{2}}
\end{aligned}
$$

and $c_{3}$ can be expressed as shown above. Inserting in Equation (C.1), using $h_{01}-h_{03}=\eta_{\mathrm{s}, \mathrm{T}}\left(h_{01}-h_{3 s s}\right)$ and canceling $h_{01}-h_{3 s s}$ yields

$$
\eta_{\mathrm{s}, \mathrm{T}}=\frac{\eta_{\mathrm{s}, \mathrm{T}}}{\eta_{\mathrm{s}, \mathrm{T}}+\Phi^{2} \Psi^{2}+\zeta_{\mathrm{R}} \Psi^{2}\left(\Phi^{2}+\left(\frac{D_{2}}{D_{3}}\right)^{2}\right)+\zeta_{N}(1-R)\left(\eta_{\mathrm{s}, \mathrm{T}}+\Phi^{2} \Psi^{2}\right) \frac{T_{3}}{T_{2}}}
$$

ignoring the trivial solution of no power output $\eta_{\mathrm{s}, \mathrm{T}}=0$ we obtain

$$
\eta_{\mathrm{s}, \mathrm{T}}=\frac{1-\Phi^{2} \Psi^{2}-\zeta_{\mathrm{R}} \Psi^{2}\left(\Phi^{2}+\left(\frac{D_{2}}{D_{3}}\right)^{2}\right)-\zeta_{N}(1-R) \Phi^{2} \Psi^{2} \frac{T_{3}}{T_{2}}}{1+\zeta_{\mathrm{N}}(1-R) \frac{T_{3}}{T_{2}}}
$$

805

where the temperature ratio across the rotor $\frac{T_{3}}{T_{2}}$ is still depending on the efficiency of the turbine, but it has limited influence on the numerical value of the efficiency 60]. However, Equation C.13 can be used to determine $\eta_{\mathrm{s}, \mathrm{T}}$ iteratively. 
Using $p_{3}=p_{4}, T_{3}$ can be expressed as $\mathrm{T}\left(p_{4}, h_{3}\right)$. The enthalpy in state 3 can be expressed as

$$
h_{3}=h_{03}-\frac{1}{2} c_{3}^{2}=h_{01}-\left(\eta_{\mathrm{s}, \mathrm{T}}+\Phi^{2} \Psi^{2}\right)\left(h_{01}-h_{3 s s}\right)
$$

where $h_{3 s s}=\mathrm{h}\left(p_{4}, \mathrm{~s}\left(p_{1}, T_{1}\right), y\right)$ and $h_{01}=h_{1}=\mathrm{h}\left(p_{1}, T_{1}, y\right)$ are known. Additional to the calculation of the isentropic efficiency of the turbine, the model allows for a preliminary design of the turbine. The blade height can be calculated from the mass flow at the rotor inlet.

$$
b_{2}=\frac{\dot{m}_{\mathrm{wf}}}{\rho_{2} c_{m 2} \pi D_{2}}
$$

The diameter of the inlet, in turn, can be calculated from conservation of mass flow rate through the rotor

$$
\begin{aligned}
& \dot{m}_{\mathrm{wf}}=\dot{m}_{\mathrm{wf}, 3}=\dot{m}_{\mathrm{wf}, 2} \\
& \Leftrightarrow D_{2}=\sqrt{\frac{4 \dot{m}_{\mathrm{wf}}}{\rho_{3} \Phi U_{2} \pi\left(\frac{D_{3 s}}{D_{2}}\right)^{2}\left(1-\left(\frac{D_{3 h}}{D_{3 s}}\right)^{2}\right)}}
\end{aligned}
$$

where $\frac{D_{3 s}}{D_{2}}$ and $\frac{D_{3 h}}{D_{3 s}}$ are fixed. The unknown meridonal velocity $c_{m 2}$ can be calculated from the velocity triangle, as

$$
c_{m 2}^{2}=c_{2}^{2}-c_{t 2}^{2}
$$

and velocity $c_{2}$ is known from Equation (C.8). The tangential velocity $c_{t 2}^{2}$ can be calculated from

$$
c_{t 2}=\frac{h_{01}-h_{03}}{\Psi \sqrt{2\left(h_{01}-h_{3 s}\right)}}
$$

Finally, Equations (C.8), (C.15), C.17), (C.19) yield

$$
b_{2}^{2}=\frac{\dot{m} \rho_{3} \Phi \Psi \sqrt{h_{01}-h_{3 s}}\left(\frac{D_{3 s}}{D_{2}}\right)^{2}\left(1-\left(\frac{D_{3 h}}{D_{3 s}}\right)^{2}\right)}{4 \rho_{2}^{2}\left(2\left(h_{01}-h_{3}\right)-R\left(h_{1}-h_{3}\right)\right)-\frac{\left(h_{01}-h_{03}\right)^{2}}{2 \Psi^{2}\left(h_{01}-h_{3 s}\right)}},
$$

where $\rho_{2}=\rho\left(p_{2}, T_{2}, y\right)$ and $\rho_{3}=\rho\left(p_{3}, T_{3}, y\right)$. 
The speed of rotation can easily be calculated as

$$
R P M=\frac{U_{2}}{D_{2}}
$$

with Equation (C.17) and $U_{2}=\Psi \sqrt{2\left(h_{01}-h_{3 s s}\right)}$. Finally, as all velocities are known, the Mach numbers in stage $x$ can be calculated as

$$
M_{x}=\frac{v_{x}}{w_{x}},
$$

${ }_{810}$ where the speed of sound $w_{x}$ is a function of PC-SAFT. 